\title{
The Emerging Global Trends in Hydrogen Energy Research for Achieving the Net Zero Goals
}

\section{Ashutosh Tiwari* (D)}

As the world is entering a phase of realization to mend ways to build a climate neutral, healthy, and sustainable environment all around and many prominent steps are taken to achieve the goal of net zero [1,2]. Advancement of materials used for energy and production purposes are being transformed and developed in ways which will ensure sustainable development without the harming of the ecology [3]. One such strong action brought is the use of hydrogen energy towards climate neutrality [4]. Hydrogen is now considered a very important product for aiming zero waste as it can make possible to remove fossil fuels usage and will play a very important role in the energy transformation of world to sustainable development goals [5]. It is very important to reduce the emission of carbon from industries and vehicles, and at the same time give a longer energy storage [6]. As the European Deal and the United Nations moves forward for attaining a net zero goals with introduction of clean hydrogen energy and its uses have been the showstopper for various conversions in various sectors which will ensure reaching the global sustainability $[7,8]$.

The research in hydrogen energy is has become very popular since the past decades. From the search results of Scopus database with the keyword "hydrogen energy", above 15000 documents with 7000 patents are found (collected on 12 October 2021) [9]. If we go through the trend, we can find that the number published articles get steep increased from 2011 and reaches maximum in 2012, when 2261 articles were published. Then suddenly, there was steep fall, but after 2015, there is growing interest in the field (Fig. 1). This is mainly due to establishment of various hydrogen energy missions and policies for clean energy.

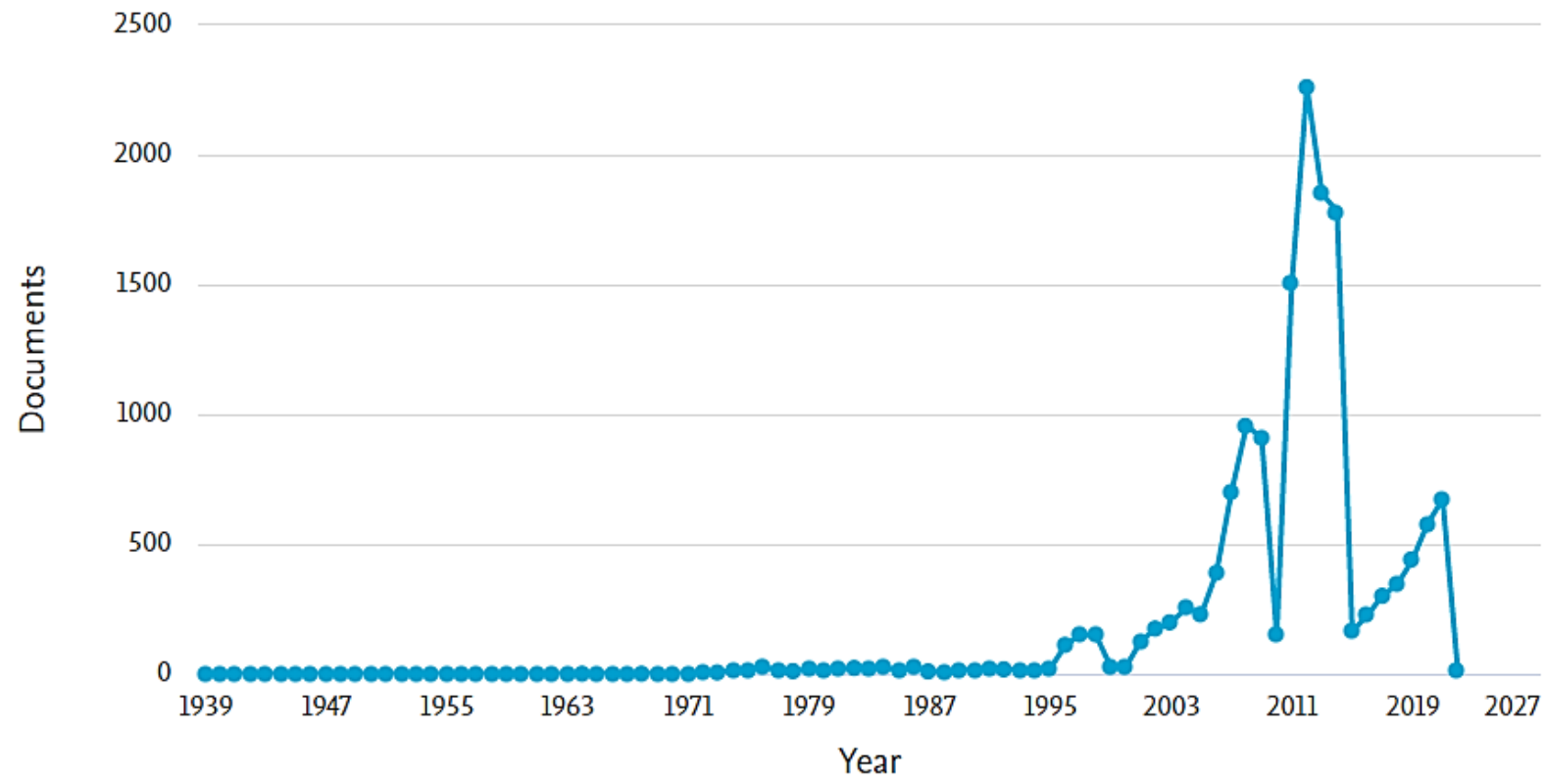

Fig. 1. Documents per year on keyword "hydrogen energy" indexed in the Scopus (collected on 07 October 2021).

Institute of Advanced Materials, IAAM, Gammalkilsvägen 18, Ulrika 590 53, Sweden

*Corresponding author: E-mail: director@iaam.se, Tel.: (+46) 1313-2424

DOI: 10.5185/aml.2021.15697 


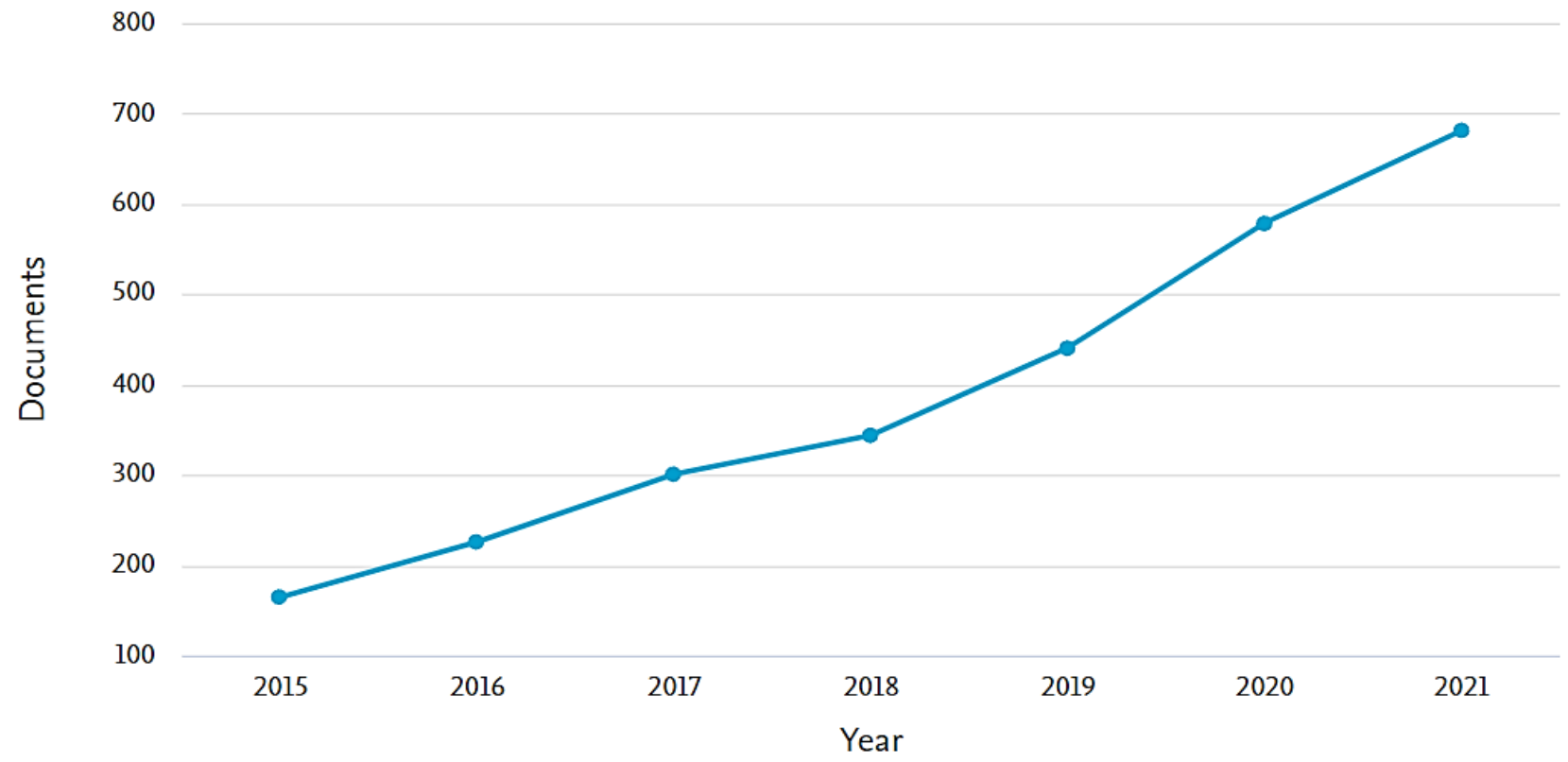

Fig. 2. Trend of documents published from the last 5 years on keyword "hydrogen energy" as indexed in the Scopus (collected on 07 October 2021).

Among the published articles, China is leading the race. Around 1250 articles have been published from China in the last 5 -years. The $2^{\text {nd }}$ position is taken by Japan with 234 articles, subsequently, $3^{\text {rd }}$ ranked- USA with 195 articles, $4^{\text {th }}$ ranked- India with 178 articles and $5^{\text {th }}$ rankedSouth Korea with 137 articles (Fig. 3). The Ministry of Education China, Chinese Academy of Sciences, Tsinghua University, Russian Academy of Sciences, University of Chinese Academy of Sciences and The University of Tokyo are the most popular affiliations can be found in the literature search (Fig. 4).
The green and/or renewable hydrogen constitutes the electrolysis of water powered by solar or wind. It has been mentioned in the European Deal in zero emission of green gas by $2050[\mathbf{4 , 1 0}]$. Hydrogen energy can perform three things which are beneficial for reducing the green gas emission [11]. It is effective in replacing fossil fuels as a zero-carbon feedstock in chemicals and fuel production [12]. Renewable hydrogen has proved itself as an essential direction for the development of green and low-carbon energy in the future as the world leadership seeks to lower greenhouse gas emissions [12].

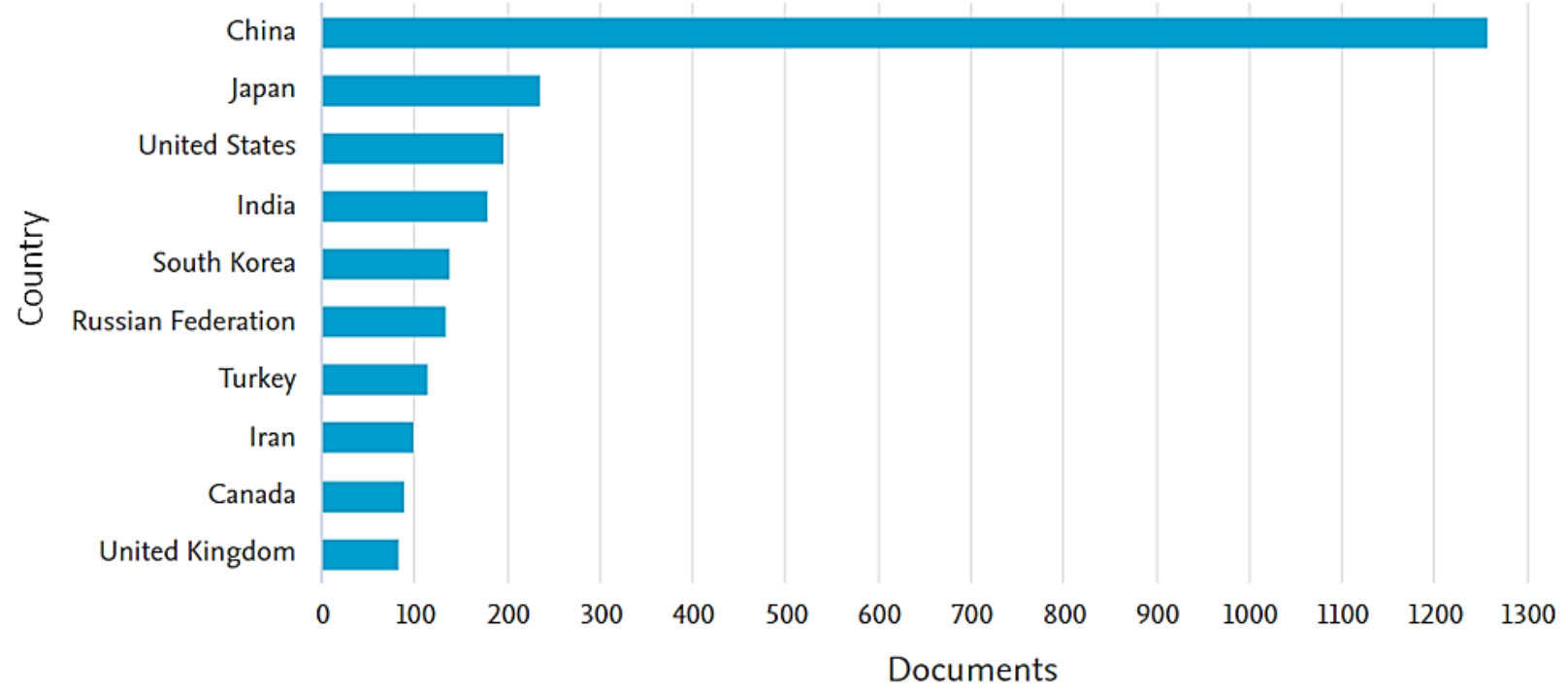

Fig. 3. Country-wise publication from the last 5 years on keyword "hydrogen energy" as indexed in the Scopus (collected on 07 October 2021). 


\section{Advanced Materials Letters https://aml.iaamonline.org}

The hydrogen energy is clean and storable with no tailpipe emission except water vapor after combustion [13]. It produces neither carbon dioxide. Hydrogen is an adaptable energy carrier which can be produced from a wide range of sources and can be used in many ways in the entire energy sector. Hydrogen proves itself as a good fuel in many cases. Its use for energy purposes does not cause greenhouse gas emissions [14]. It can also be used to produce other gases as well as liquid fuels. Existing infrastructure like gas transport and gas storage can be repurposed for hydrogen. On the basis of its properties, it has a higher density than batteries so can be used for long distance and heavy goods transport.

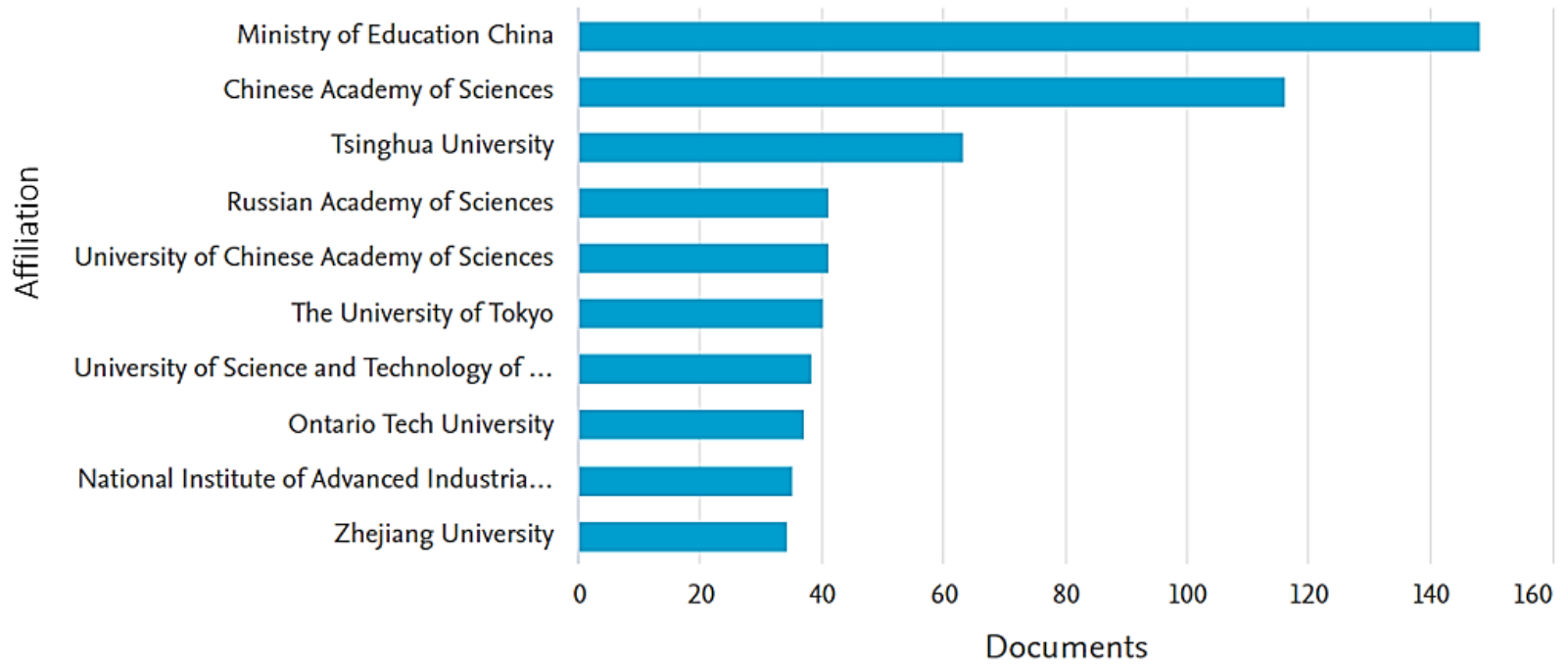

Fig. 4. Most popular affiliations from the last 5 years on hydrogen energy (collected from Scopus database on 07 October 2021).

The hydrogen produces neither carbon dioxide nor pollutants such as sulfur oxide and nitrogen oxide. Low carbon hydrogen can be a transition fuel which will avoid stranded assets and prepare the world to shift to a new way to deliver energy, which is environmentally friendly as well as economical [15]. If we analyze the popular authors in this field, we found that Prof. Kazunari Domen from Shinshu University, Japan published the most articles on hydrogen energy. The world top ranked author is followed by Prof. Ibrahim Dincer from Ontario Tech University,
Canada; Prof. Takashi Hisatomi from Shinshu University, Japan; Prof. Tsutomu Minegishi from University of Tokyo, Japan; Prof. Masao Katayama from University of Tokyo, Japan; Muhammad Bilal Tahir from University of Gujrat and University of Sialkot, Gujrat, Pakistan, Prof. Tiejiang Yuan from Dalian University of Technology, China; Prof. Taro Yamada from University of Tokyo, Japan; Prof. Fatih Şen from Dumlupinar Üniversitesi, Turkey; Dr. J. Dufour from Instituto IMDEA Energía, Spain and so on (Fig. 5).

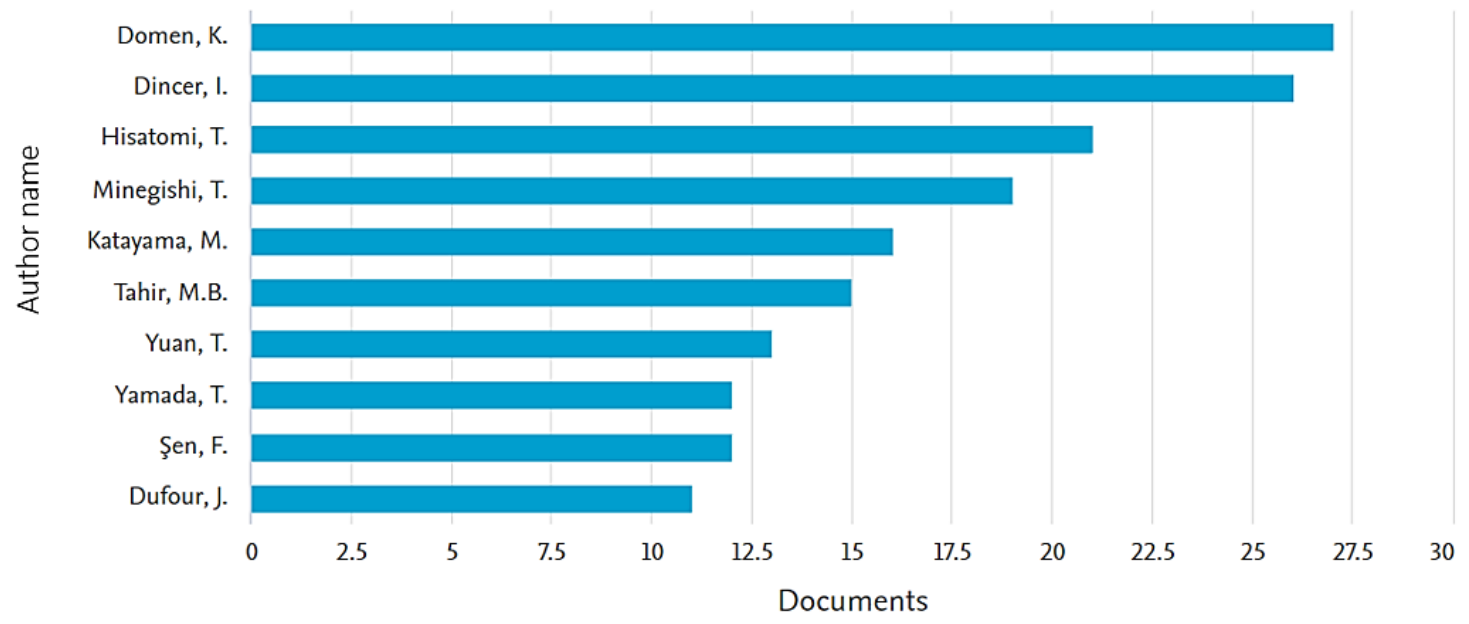

Fig. 5. Most popular authors published articles on the 'hydrogen energy' research from the last 5 years (collected from Scopus database on 07 October 2021). 
Among the funding agencies, the National Natural Science Foundation of China has funded the greatest number of research and in top of the list with above 700 articles. If we look at the top five funding agencies, all of them are from China with National Natural Science
Foundation of China, the others are Fundamental Research Funds for the Central Universities, Ministry of Education of the People's Republic of China, National Key Research and Development Program of China, Ministry of Science and Technology of the People's Republic of China (Fig. 6).

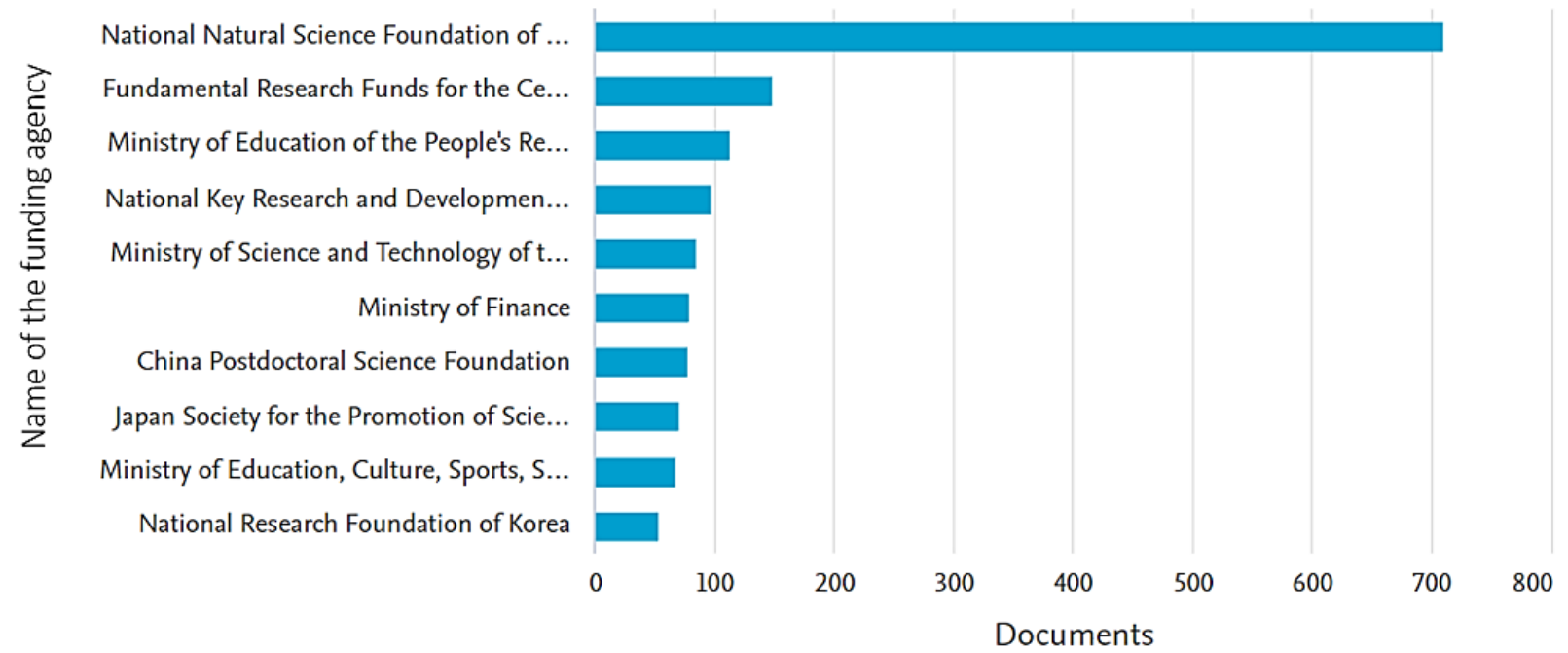

Fig. 6. Top funding agencies in last 5 years on hydrogen energy (collected from Scopus database on 07 October 2021).

The global leadership of all the advanced and developing countries are now focusing on the fact that clean hydrogen will play an important role in the saving of the environment and lower the emission of Green Gas and at the same time ensure a sustainable development all around [16]. The International Energy Agency of Europe acclaimed its high potential in its report on hydrogen in June 2019. Bloomberg New Energy Finance said clean hydrogen "can help address the toughest third of global greenhouse gas emissions by 2050" in March 2020 [4]. After the pandemic hydrogen economy has been termed as a priority for the European Deal's post-COVID-19 economic policies [18]. The European Green Deal has high emphasis on the use of clean hydrogen for achieving a climate neutral Europe by 2050 for which it has aimed for a 55\% emission reduction target for 2030 [19]. The European Commission has embarked on ideas for using innovative energy carriers such as hydrogen, particularly coming from renewable electricity [20]. The People's Republic of China is also vouching for Renewable hydrogen as an essential direction for the development of green and low-carbon energy in the future and aims to lower greenhouse gas emissions [21]. Low carbon hydrogen is an important initiative right now for countries around the world. In 2020, the world's production of hydrogen was approximately 72 million tons [22]. The People's Republic of China produced about 20 million tons in 2019 [21]. One percent or less was renewable energy hydrogen with the remainder being hydrogen produced from fossil energy and from industrial by-products.
However, with all the plus points of hydrogen energy aiming for climate neutrality comes some limitations too [23]. It is very crucial on the entire process of how hydrogen is made which only can ensure its proper usage. Only the green' or 'renewable' hydrogen is made from the electrolysis of water powered by renewables will prove fruitful for the ultimate SDGs [24]. Clean hydrogen faces a paradox in its business case. Companies are reluctant to pay several times the price for a climate-friendly alternative in the form of green hydrogen. Most hydrogen energy still produces the carbon dioxide that contributes to climate change [25]. More than $95 \%$ of hydrogen energy is produced using fossil fuels containing carbon in all around the world.

As the world governance joins in a noble movement of achieving a climate neutral sustainable healthy environment for the future generation to come hydrogen energy is gaining maximum importance and its credits are worth settling for. Green hydrogen gives renewables a business case when the electricity cannot [26]. The hydrogen economy is an international project as crossborder cooperation can be seen in many countries like North Korea, Europe, North Africa, Middle East and even Australia and Chile [4]. The People's Republic of China's annual demand for hydrogen will reach 60 million tons by 2050 [27]. Japan has many important projects which includes Hydrogen usage [28]. Many countries including Australia, Saudi Arabia and Brunei are determining the best way to transport green or blue hydrogen over large distances by ship [29]. The Dutch government is aiming to 


\section{Advanced Materials Letters https://aml.iaamonline.org}

broaden its low-carbon program [30]. These will all result in the market-driven activation of blue hydrogen projects and, depending on the costs ii is hoped that green hydrogen projects in the near future will gain great momentum. France's own hydrogen strategy includes indicative targets for transformation of grey hydrogen to green hydrogen in industry which is only helpful in the saving of the environment [31]. The French government has set targets of usage of green hydrogen in industries to achieve the goals of sustainable development and clean and green environment. Germany also aims to organize combined auctions of offshore wind fields for electrolysis, which would imply connecting the value chain in one single tender [32]. The global garners up to bring hydrogen energy in the forefront with the aim of climate neutrality, a clean and net zero environment is definitely on the way.

\section{References}

1. Tiwari, A.; Transforming Energy Technologies for Climate Neutrality Goals, Adv. Mater. Lett., 2021, 12, 21091658.

2. Forster, P.M., Forster, H.I., et al., Current and future global climate impacts resulting from COVID-19, Nat. Clim. Chang., 2020, 10, 913-919.

3. Tiwari, A., Advancing Materials towards Climate Neutrality by 2050, Adv. Mater. Lett., 2021, 12, 21081650.

4. Renssen, S.V., The hydrogen solution?. Nat. Clim. Chang., 2020, 10, 799-801.

5. Staffell, I., Scamman, D., et al., The role of hydrogen and fuel cells in the global energy system, Energy Environ. Sci., 2019, 12, 463491.

6. Gielen, D., Boshel, F., et al., The role of renewable energy in the global energy transformation, Energy Strategy Reviews 2019, 24, 3850 .

7. "2050 long-term strategy", Accessed on 12 October 2021, $<$ https://ec.europa.eu/clima/eu-action/climate-strategiestargets/2050-long-term-strategy_en $>$.

8. "Net Zero by 2050", Accessed on 12 October 2021, $<$ https://www.iea.org/reports/net-zero-by-2050>.

9. "Scopus", Accessed on 12 October 2021, $<$ https://www.scopus.com/search/form.uri?display=basic\#basic $>$.

10. Momirlan M., Veziroglu T.N., Current status of hydrogen energy, Renewable and Sustainable Energy Reviews, 2002, 6, 141-179.

11. "Economics of Biofuels", Accessed on 12 October 2021, $<$ https://www.epa.gov/environmental-economics/economicsbiofuels $>$

12. Pickl, M.J., The renewable energy strategies of oil majors - From oil to energy? Energy Strategy Reviews, 2019, 26, 100370.

13. "Hydrogen energy", Accessed on 12 October 2021, $<$ https://thehimalayantimes.com/blogs/hydrogen-energy $>$.

14. "Hydrogen Benefits and Considerations", Accessed on 12 October 2021, <https://afdc.energy.gov/fuels/hydrogen_benefits.html>.

15. "The role of oil and gas companies in the energy transition", Accessed on 12 October 2021, <https://www.atlanticcouncil.org/indepth-research-reports/report/the-role-of-oil-and-gas-companies-inthe-energy-transition/>.

16. Dahlke, S., Sterling, J., Meehan, C., Policy and market drivers for advancing clean energy, In Advances in Clean Energy Technologies, Azad, A.K. (Ed.), DOI: 10.1016/B978-0-12-821221-9.00012-8.

17. "The Future of Hydrogen", Accessed on 12 October 2021, $<$ https://www.iea.org/reports/the-future-of-hydrogen>.

18. "Opportunities of post COVID-19 European recovery funds in transitioning towards a circular and climate neutral economy, Accessed on 12 October 2021, $<$ https://www.europarl.europa.eu/RegData/etudes/BRIE/2020/6581 86/IPOL_BRI(2020)658186_EN.pdf>.
19. "A European Green Deal", Accessed on 12 October 2021, $<$ https://ec.europa.eu/info/strategy/priorities-2019-2024/europeangreen-deal_en>.

20. "EU hydrogen policy", Accessed on 12 October 2021, $<$ https://www.europarl.europa.eu/RegData/etudes/BRIE/2021/6893 32/EPRS BRI(2021)689332 EN.pdfs.

21. "Five expert views on China's pledge to become carbon neutral by 2060", Accessed on 12 October 2021,

$<$ https://odi.org/en/insights/five-expert-views-on-chinas-pledge-tobecome-carbon-neutral-by-2060/>.

22. "Department of Energy Hydrogen Program Plan", Accessed on 12 October 2021, <https://www.hydrogen.energy.gov/pdfs/hydrogenprogram-plan-2020.pdf $>$.

23. "In-depth Q\&A: Does the world need hydrogen to solve climate change?", Accessed on 12 October 2021

$<$ https://www.carbonbrief.org/in-depth-qa-does-the-world-needhydrogen-to-solve-climate-change $>$.

24. "Hydrogen: A Renewable Energy Perspective", Accessed on 12 October 2021, <https://www.irena.org//media/Files/IRENA/Agency/Publication/2019/Sep/IRENA_Hydro gen 2019.pdf>.

25. "Why We Need Green Hydrogen", Accessed on 12 October 2021, $<$ https://news.climate.columbia.edu/2021/01/07/need-greenhydrogen/>

26. "So, What Exactly Is Green Hydrogen?", Accessed on 12 October 2021, <https://www.greentechmedia.com/articles/read/greenhydrogen-explained $>$

27. "Hydrogen energy could be key to carbon neutrality in the People's Republic of China", Accessed on 12 October 2021, < https://blogs.adb.org/blog/hydrogen-energy-could-be-key-carbonneutrality-people-s-republic-china>.

28. "Japan has many important projects which includes Hydrogen usage", Accessed on 12 October 2021,

$<$ https://www.ifri.org/sites/default/files/atoms/files/nagashima_japa n_hydrogen_2020.pdf $>$.

29. "The clean hydrogen future has already begun", Accessed on 12 October 2021, <https://www.iea.org/commentaries/the-cleanhydrogen-future-has-already-begun>

30. "Central government encourages sustainable energy", Accessed on 12 October 2021, <https://www.government.nl/topics/renewableenergy/central-government-encourages-sustainable-energy>.

31. "The Future of Hydrogen", Accessed on 12 October 2021, $<$ https://www.capenergies.fr/wpcontent/uploads/2019/07/the future_of_hydrogen.pdf $>$.

32. "The German Hydrogen Strategy", Accessed on 12 October 2021 , $<$ https://www.wfw.com/articles/the-german-hydrogen-strategy/> 